\title{
Application Cloud Point Extraction Method Joined with Liquid Ion Exchange for Selective Determination of $\mathrm{Fe}^{3+}$ and $\mathrm{Hg}^{2+}$ in Real Samples
}

\author{
${ }^{1}$ Shawket Kadhim Jawad, ${ }^{1}$ Musa Umran Kadhium and ${ }^{2}$ Ebaa Adnan Azooz \\ ${ }^{1}$ Department of Chemistry, Faculty of Education for Girls, University of Kufa, Al-Najaf, Iraq \\ ${ }^{2}$ General Directorate of Education, Al-Thakawat School, Al-Najaf Al-Ashraf, Iraq
}

\begin{abstract}
By using two approaches cloud point extraction technology CPE and liquid ion exchange to separate and extracted $\mathrm{Fe}(\mathrm{III})$ and $\mathrm{Hg}(\mathrm{II})$ ions from acidic $\mathrm{HCl}$ media as ion pair association complexes by using new laboratory prepared 2-(4-hydroxy phenyl azo)-4-benzene naphthol (HPBN) whereas the spectrophotometric studies show the new organic reagent (HPBN) have a wave length for maximum absorbance was $\lambda_{\max }=450 \mathrm{~nm}$, the ion pair association complex of $\mathrm{Fe}^{3+} \lambda_{\max }=477 \mathrm{~nm}$ but for $\mathrm{Hg}^{2+} \lambda_{\max }=476 \mathrm{~nm}$, so that, the optimum condition for high extraction efficiency was $0.5 \mathrm{M} \mathrm{HCl}$ for both ions , $100 \mu \mathrm{g}$ metal ions in $10 \mathrm{~mL}$ aqueous solution $1 \times 10^{-4}$ $\mathrm{M}$ of HPBN and necessary to heating the solution at $90^{\circ} \mathrm{C}$ for $20 \mathrm{~min}$ to $\mathrm{Fe}^{3+}$ ion and $15 \mathrm{~min}$. For $\mathrm{Hg}^{2+}$ ion and in presence of $0.5 \mathrm{~mL}$ Triton X-100 for $\mathrm{Fe}^{3+}$ and $0.8 \mathrm{~mL}$ Triton X-100 for $\mathrm{Hg}^{2+}$ ion. As well as the research involved other studies such as electrolyte effect interferences effect, stoichiometry, application and determination of trace amounts of $\mathrm{Fe}(\mathrm{III})$ and $\mathrm{Hg}$ (II) in environmental sample by spectrophotometry.
\end{abstract}

Key words: Cloud point extraction, liquid ion exchange, 2-(4-hydroxy phenyl azo)-4-benzene naphthol (HPBN), mercury, iron, $\mathrm{Hg}$ (II)

\section{INTRODUCTION}

Cloud Point Extraction (CPE) is sensitive, simple method to determine many of the micro amount elements from various chemical and biological systems (Tokalioglu et al., 2000; Samaddar and Sen, 2014). The system depend on using surfactants and that too at low concentrations at specific temperatures to form clouds that separate out from the aqueous solution (Jawad and Azooz, 2014, 2015a, b; Jawad and Hayder, 2015). Liquid ion exchange method consider as indirect method for extraction metal ions as oxyanions or hallo anion complexes after formation ion pair association complexes by using suitable reagent in acidic medium this method very sensitively to extraction $\mathrm{Cd}^{2+}$ and $\mathrm{Hg}^{2+}$ ions by using many organic reagent (Jawad and Hameed, 2017). By joined liquid ion exchange and $\mathrm{CPE}$ as extracted $\mathrm{Pt}(\mathrm{II})$ ion from acidic $\mathrm{HCl}$ media as ion pair association complexes by using Janus green $\mathrm{B}(\mathrm{JG}) 1 \times 10^{-4} \mathrm{M}$ and $0.5 \mathrm{~mL}$ TritonX-100 after heating at $75^{\circ} \mathrm{C}$ for $15 \mathrm{~min}$. The complex extracted was $\left[\mathrm{JG}^{+} ; \mathrm{HptCl}_{4}{ }^{-}\right.$] (Jawad and Salih, 2015). Use crown ether DB18C6 and from $\mathrm{Hcl}$ media extracted $\mathrm{Fe}^{3+}$ ion by CPL after change $\mathrm{Fe}^{3+}$ into $\mathrm{FeCl}_{4}$-TritonX-100 was necessary to obtained higher extraction efficiency, there are another empirical application for this study in real sample. By using new reagent 3-[(2-pyridyl azo)]-1-nitroso-2-naphthol (PANN) from acidic media of $1 \mathrm{M} \mathrm{HCl}$ as a liquid ion exchanger for extraction $\mathrm{Zn}^{2+}$ by application CPL with presence $0.6 \mathrm{~mL}$ TritonX-100 and determination $\mathrm{Zn}^{2+}$ in different samples (Jawad and Azooz, 2015a, b). For extraction and determination of $\mathrm{Fe}^{3+}$ and $\mathrm{Hg}^{2+}$ ions from aqueous solution using onium system coupled with $\mathrm{CPE}$ in presence of BAEE from $\mathrm{HCl}$ aqueous solution and TritonX-100 as surfactant. As well as the research involved other studies such as electrolyte effect interferences effect, application for determination of $\mathrm{Fe}^{3+}$ ion and $\mathrm{Hg}^{2+}$ ion in biologic samples (Jawad et al., 2017).

\section{MATERIALS AND METHODS}

Experimental: For spectroscopic studies and absorbance measurements used double beam spectrophotometer Biochrom Model (80-7000-11) Libra S60 Cambridge CB40FJ with $1.00 \mathrm{~cm}$ quartz cell and FTIR spectrophotometer Shimadzu FTIR 8400 series (Japan), so that, used Electrostatic water bath (WNB7-45) (England) for heating to CPT as well as all experiments needed balance (A \& D Company, Limited, Dool, CE, HR 200, Japan) $( \pm 0.0001 \mathrm{~g})$.

Materials and solution:s For preparing all the solutions needing in experiment used high purity materials received from commercial sources without further purification and

Corresponding Author: Shawket Kadhim Jawad, Department of Chemistry, Faculty of Education for Girls, University of Kufa, Al-Najaf, Iraq 
used doubly distilled water with set of suitable glassware, stock solution $1 \mathrm{mg} / \mathrm{mL}$ of $\mathrm{Fe}^{3+}$ ion prepared by dissolving $0.2880 \mathrm{~g}$ of $\mathrm{FeCl}_{3}$ in $100 \mathrm{~mL}$ and for $\mathrm{Hg}^{2+}$ ion dissolved $0.1353 \mathrm{~g}$ of $\mathrm{HgCl}_{2}$ in $100 \mathrm{~mL}$ of distilled water other working solutions preparing by dilution with distilled water in suitable volumetric flask, so, $1 \times 10^{-2} \mathrm{M}$ of HPBN was prepared by dissolving $0.0850 \mathrm{~g}$ in $25 \mathrm{~mL}$ distilled water contain TritonX-100. Other working solutions were prepared by dilution method with distilled water.

Comprehensive method: Aqueous solutions $10 \mathrm{~mL}$ in volume contain $100 \mu \mathrm{g}$ of $\mathrm{Fe}^{3+}$ or $\mathrm{Hg}^{2+}$ with optimum concentration $\mathrm{HCl}$ and $1 \times 10^{-4} \mathrm{M} \mathrm{HPBN}$ in the presence optimum volume of surfactant $1 \%$ TritonX-100. Heating the solution in electrostatic water bath for suitable temperature and time until formation Cloud Point Layer then separated CPL from aqueous solution and dissolved CPL in $5 \mathrm{~mL}$ ethanol. The absorbance of alcoholic solution is measured at $\lambda_{\max }=477 \mathrm{~nm}$ for $\mathrm{Fe}^{3+}$ and $\lambda_{\max }=476 \mathrm{~nm}$ for $\mathrm{Hg}^{2+}$ ion against blank prepared in the same manner without metal ions. But aqueous solution for $\mathrm{Fe}^{3+}$ ion treated according to thiocyanate method but $\mathrm{Hg}^{2+}$ ion treated according to Dithizone spectrophotometric method (Marczenko and Balcerzak, 2000) to determine the remainder quantity of metal ions in aqueous solution after extraction and subtraction this quantity from original quantity $100 \mu \mathrm{g}$ to determine the transferred quantity to CPL to formation ion pair association complex extracted then calculated Distribution ratio (D) according to relation Eq. 1:

$$
\mathrm{D}=\frac{\left[\mathrm{M}^{\mathrm{n}+}\right]_{\mathrm{CPL}}}{\left[\mathrm{M}^{\mathrm{n}+}\right]_{\mathrm{aq}}}
$$

Whereas:

$$
\mathrm{M}^{+\mathrm{n}}=\mathrm{Fe}^{3+} \text { or } \mathrm{Hg}^{2}
$$

\section{RESULTS AND DISCUSSION}

The laboratory preparing of the new organic reagent HPBN (Shibata et al., 1976) demonstrate according to mechanism (Fig. 1).
Spectrophotometric studies: The spectrum of new organic reagent HPBN dissolved in aqueous solution contain some drops of TritonX-100 shows wave length of maximum absorbance was $\lambda_{\max }=450 \mathrm{~nm}$ as in Fig. 1. FTIR for this reagent appear as in Fig. 2. So that, to determining the wave length of maximum absorbance of ion pair association complex extracted for each metal ion under study, taking $10 \mathrm{~mL}$ aqueous solutions contain $100 \mu \mathrm{g}$ of metal ion $\mathrm{Fe}^{3+}$ or $\mathrm{Hg}^{2+}$ in the existence of $0.5 \mathrm{~mL}$ $\mathrm{HCL}, 1 \times 10^{-4} \mathrm{M}(\mathrm{HPBN}), 0.5 \mathrm{~mL}$ of TritonX-100. Heating the solution at $90^{\circ} \mathrm{C}$ for $15 \mathrm{~min}$ until formation Cloud Point Layer CPL, separating CPL and dissolved in $5 \mathrm{~mL}$ of ethanol and then taking UV-VIS. Absorption spectrum to the alcoholic solution the results demonstrate in Fig. 2-5

The spectra shows wave length of maximum absorption of HPBN was $\lambda_{\max }=450 \mathrm{~nm}$, IR spectrum show peak at wave number $3400 \mathrm{~cm}^{-1}$ belong to stretching vibration $-\mathrm{OH}$ group for naphthol but aromatic $\mathrm{C}-\mathrm{H}$ appear at 3061-2973 $\mathrm{cm}^{-1}$, Bending vibration for phenolic $\mathrm{C}-\mathrm{O}$ giving peak at $1303 \mathrm{~cm}^{-1}$, also, peak at $1585 \mathrm{~cm}^{-1}$ for $\mathrm{C}=\mathrm{C}$ aromatic as well as the weak peaks at $1450-1350 \mathrm{~cm}^{-1}$ belong to $\mathrm{N}=\mathrm{N}$ also the region1510-1100 $\mathrm{cm}^{-1}$ belong to all the peaks for vibration of bridge azo group also the peak at $762 \mathrm{~cm}^{-1}$ for naphthol ring in finger print region. As well as the wave length of maximum absorbance for ion pair complex of $\mathrm{Fe}^{3+}$ was $\lambda_{\max }=477 \mathrm{~nm}$ but ion pair association complex of $\mathrm{Hg}^{2+}$ was $\lambda_{\text {max }}=476 \mathrm{~nm}$ using these wave length to measurement the absorbance of CPL solutions whereas the absorbance appear as a function to the concentration of ion pair complex extracted into CPL.

Effect of hydrochloric acid concentration: The $10 \mathrm{~mL}$ aqueous solutions contain $100 \mu \mathrm{g}$ of $\mathrm{Fe}^{3+}$ or $\mathrm{Hg}^{2+}$ with different concentration of HCL and $0.5 \mathrm{~mL}$ of $1 \%$ TritonX-100 and $1 \times 10^{-4} \mathrm{M}$ HPBN. Heating these solutions in electrostatic water bath at suitable temperature and time to produce CPL with good properties then separated CPL from aqueous solution and complete the procedure according to comprehensive method. The results were as in Fig. 6 and 7.

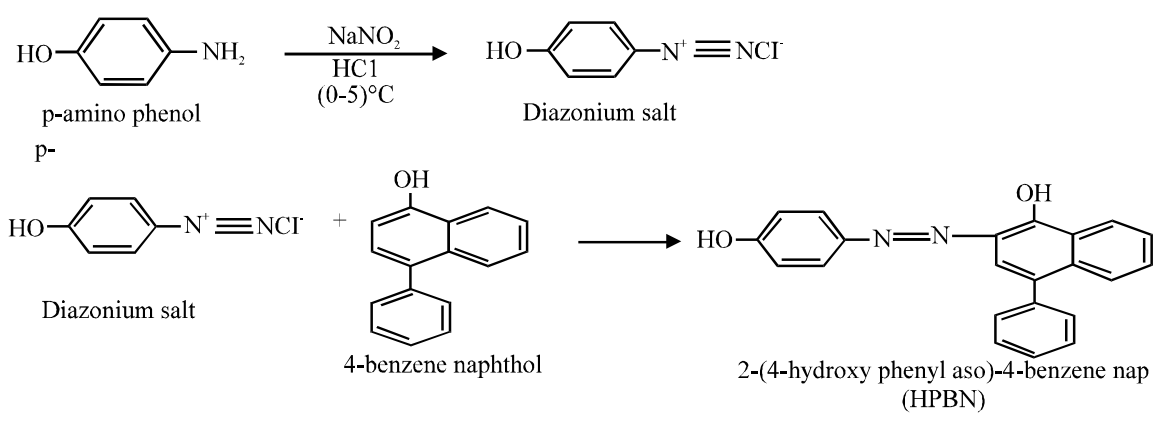

Fig. 1: Wave length of maxmimum absorbance 


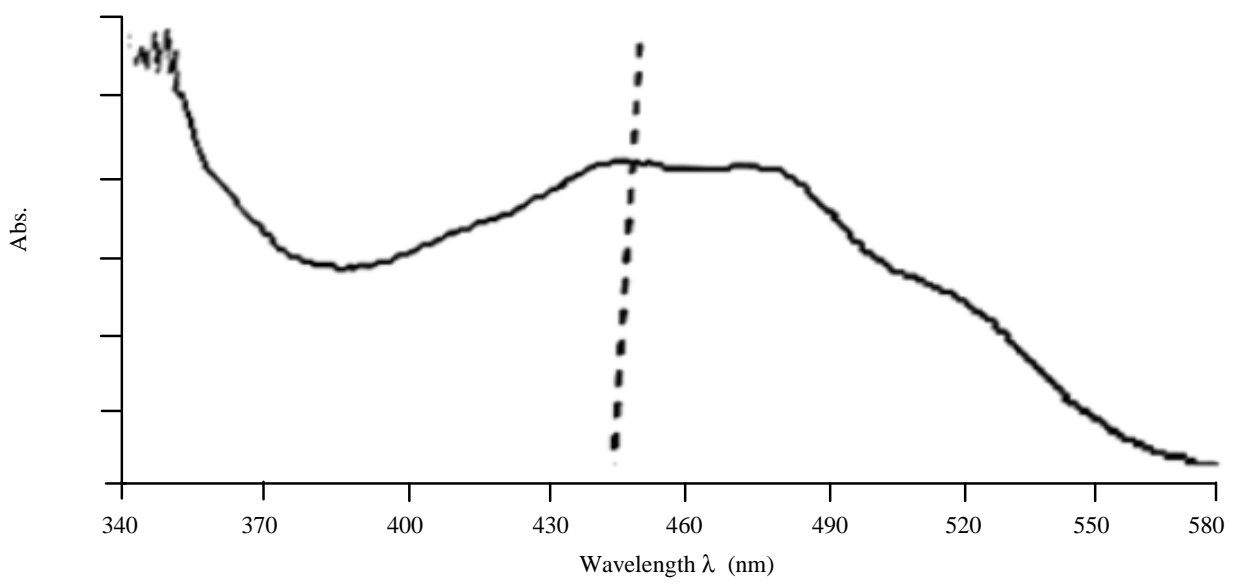

Fig. 2: UV-VIS absorption spectrum of organic reagent $\mathrm{HPBN}(\lambda 450.0 \mathrm{~nm})$

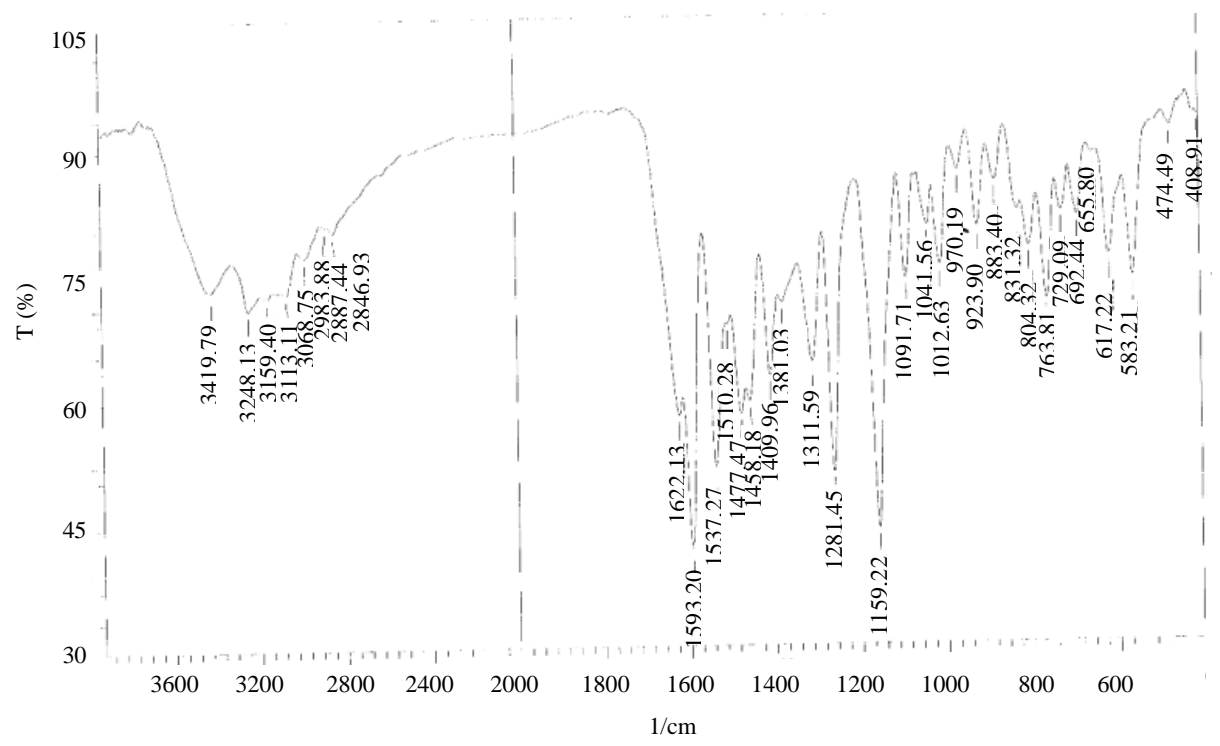

Fig. 3: FTIR spectrum for new organic reagent $\operatorname{HPBN}(\lambda 477.0 \mathrm{~nm})$

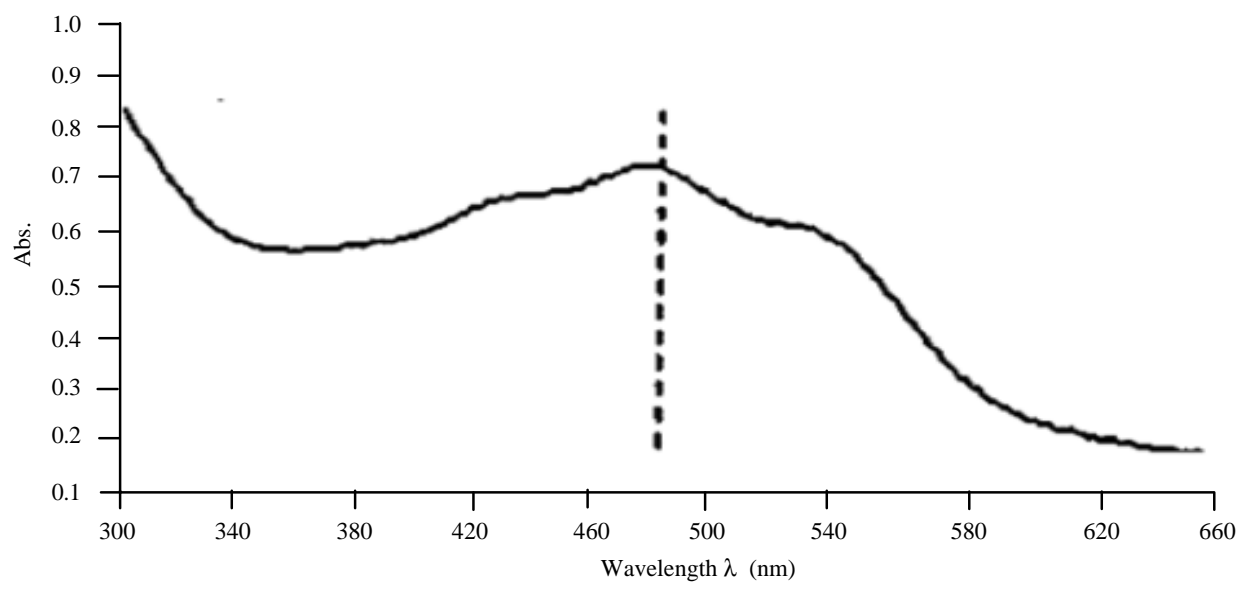

Fig. 4: UV-VIS absorption spectrum of ion pair association complex of $\mathrm{Fe}^{3+}$ extracted $(\lambda .476 .0 \mathrm{~nm})$ 


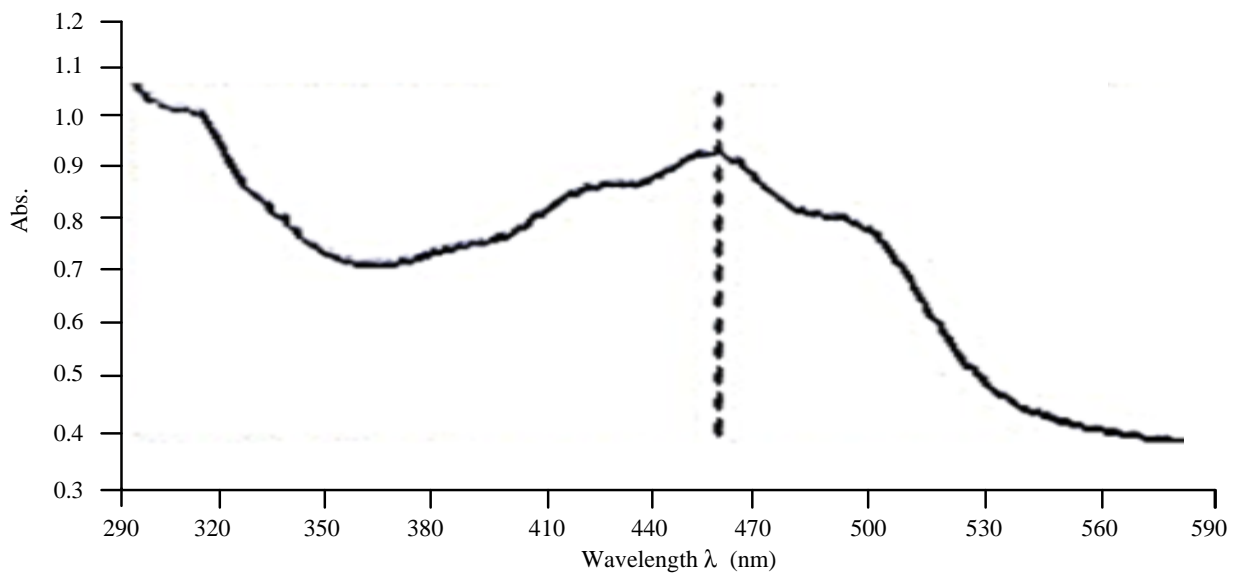

Fig. 5: UV-VIS absorption spectrum of ion pair association complex of $\mathrm{Hg}^{2+}$ extracted

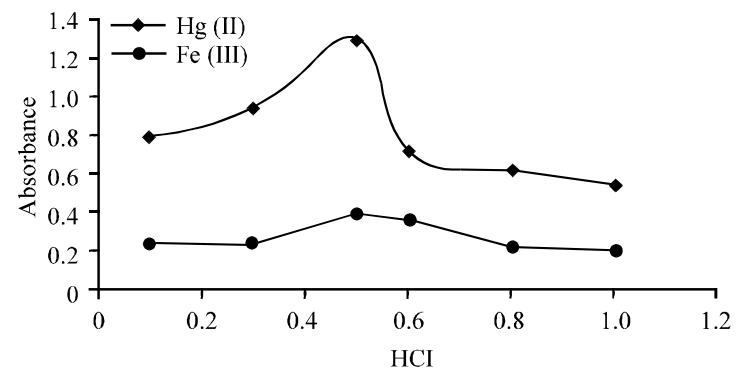

Fig. 6: Effect of $\mathrm{HCl}$ concentration on formation and stability of ion pair association complex extracted

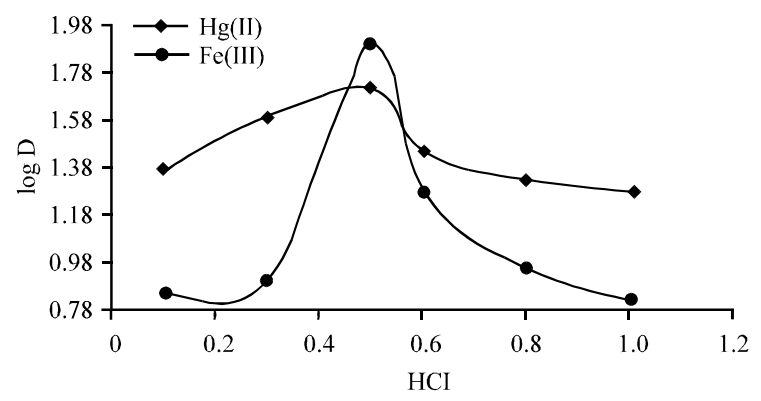

Fig. 7: Effect of $\mathrm{HCl}$ concentration on extraction efficiency and $D$ values

The results shows $0.5 \mathrm{M} \mathrm{HCl}$ was the optimum concentration of $\mathrm{HCl}$ for extraction both metal ions at this $\mathrm{HCl}$ concentration reached to favorable equilibrium of formation ion pair association complex and extraction the mechanism of extraction were as equilibria:

$$
\begin{array}{ll}
4 \mathrm{HCI}+\mathrm{Fe}^{3+} \square & \mathrm{FeCI}_{4}{ }^{-}+4 \mathrm{H}^{+} \\
3 \mathrm{HCI}+\mathrm{Hg}^{2+} \square & \mathrm{HgCl}_{3}^{-}+3 \mathrm{H}^{+}
\end{array}
$$

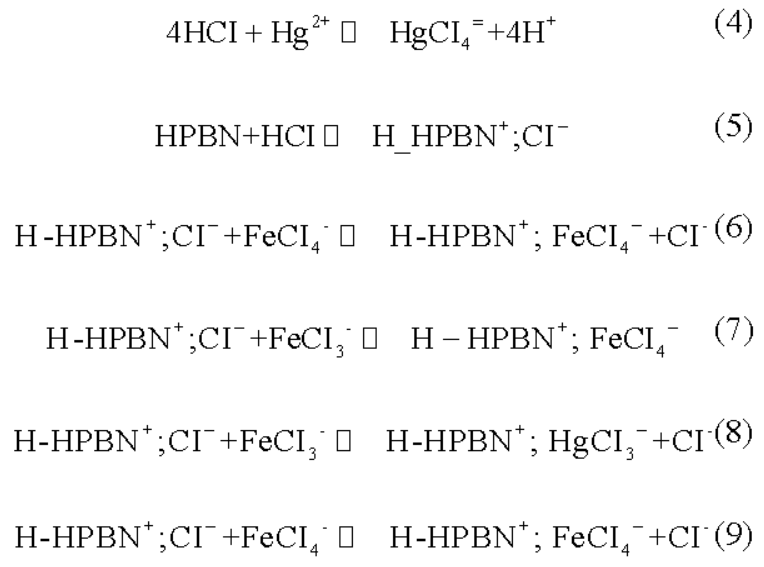

Any concentration of $\mathrm{HCl}$ less then optimum not enough to reached equilibrium and effect to decrease the concentration of anion chloro complex and ion exchanger $\mathrm{H}-\mathrm{HPBN}{ }^{+}, \mathrm{Cl}^{-}$and decrease in extraction efficiency, so that, any concentration of $\mathrm{HCl}$ more than optimum effect to decrease extraction efficiency also because effect to decrease concentration of anion chloro complex formation according to mass action low and by formation stable compound for metal ion not extracted.

Effect of metal ions concentration: Preparing two set of $10 \mathrm{~mL}$ aqueous solutions, the first set contain different concentration of $\mathrm{Fe}^{3+}$ but the second set contain rising concentration of $\mathrm{Hg}^{2+}$ and each solution of the two sets exist $0.5 \mathrm{M} \mathrm{HCl}$ and $0.5 \mathrm{~mL}$ TritonX- 100 and $1 \times 10^{-4} \mathrm{M}$ HPBN. Heating all these solutions in electrostatic water bath at suitable temperature and time to produce $\mathrm{CPL}$ with good proportion then separated CPL from aqueous solution and complete the working as in comprehensive method. The results were as in Fig. 8 and 9.

The results show there is a straight line relation between absorbance, so, distribution ratio with metal ions 


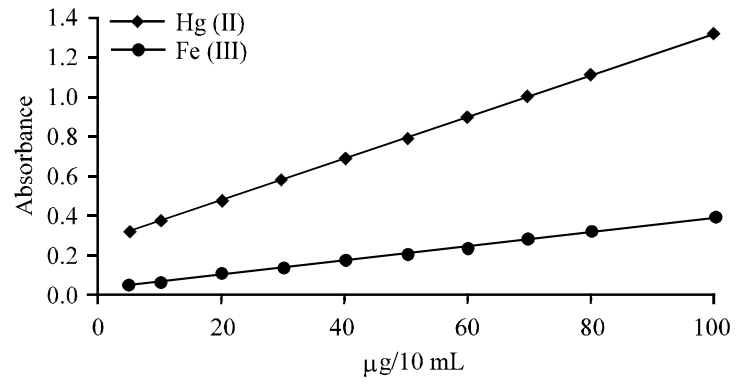

Fig. 8: Effect of metal ions concentration on formation and stability of ion pair complex

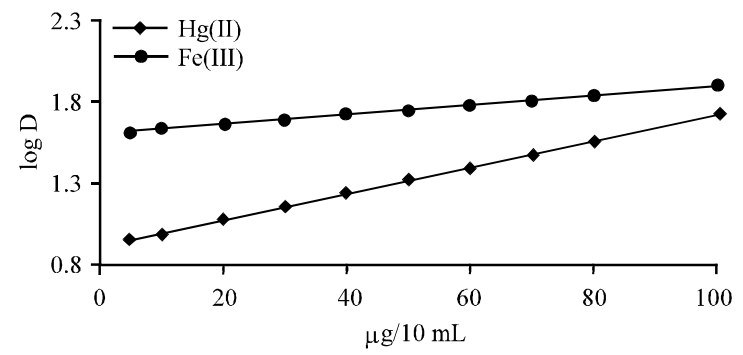

Fig. 9: $\mathrm{D}=\mathrm{f}[$ metal ions $]$

concentration in aqueous solution and this straight line relation continue to $100 \mu \mathrm{g}$ metal ion in limit aqueous solutions then deviation in the presence more, this explain effect of metal ion concentration as thermodynamic parameter on equilibrium of formation ion pair association and extracted and that is mean the increasing of metal ion concentration effect to increase the rate of forward direction of equilibrium relation and increase ion pair association complex extracted until $100 \mu \mathrm{g}$ more than that effect to decline extraction efficiency because effect to increase the rate of backward direction of equilibrium that is mean relation increase dissociation of complex according to mass action law.

Effect of temperature: According to comprehensive method extracted $100 \mu \mathrm{g}$ of $\mathrm{Fe}^{3+}$ and $\mathrm{Hg}^{2+}$ from $10 \mathrm{~mL}$ aqueous solution at optimum conditions in different temperature at constant time of heating the results were as in Fig. 10 and 11.

The results appear increase in ion pair association complex concentration extracted and extraction efficiency with rising temperature to optimum value $90^{\circ} \mathrm{C}$, then calculated extraction constant $\mathrm{K}_{e x}$ at rising temperature by following the relation Eq. 2 :

$$
\mathrm{K}_{\mathrm{ex}}=\frac{\mathrm{D}}{\left[\mathrm{M}^{\mathrm{n}+}\right][\mathrm{BAEE}]}
$$

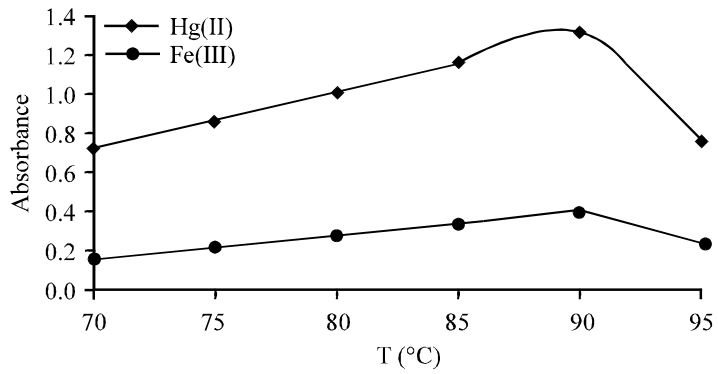

Fig. 10: Effect temperature on CPL formation and ion pair complex extracted

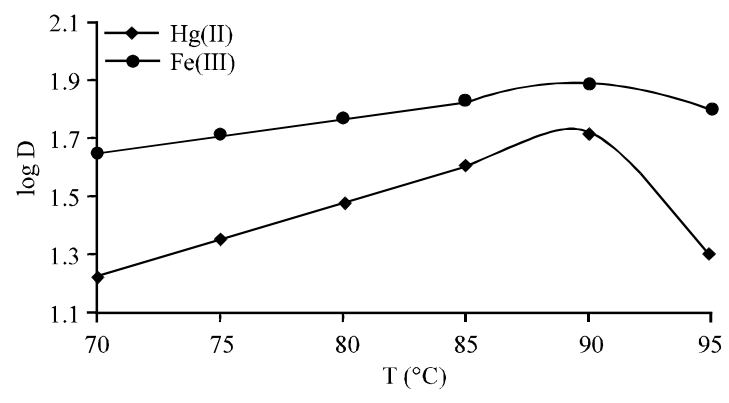

Fig. 11:Effect temperature on extraction efficiency and D-value

Table 1: Thermodynamic data of extraction

\begin{tabular}{lccc}
\hline Metal ions & $\Delta \mathrm{h}_{\mathrm{ex}}\left(\mathrm{kJ} \mathrm{mol}^{-1}\right)$ & $\Delta \mathrm{g}_{\mathrm{ex}}\left(\mathrm{kJ} \mathrm{mol}^{-1}\right)$ & $\Delta \mathrm{S}_{\mathrm{ex}} \mathrm{J}\left(\mathrm{mol}^{-1} \mathrm{~K}^{-1}\right)$ \\
\hline $\mathrm{Fe}^{3+}$ & 0.0266 & -65.604 & 180.800 \\
$\mathrm{Hg}^{2+}$ & 0.0547 & -68.082 & 187.980 \\
\hline
\end{tabular}

Diagram $\log \mathrm{K}_{\mathrm{ex}}$ against 1/T $\mathrm{K}$ as in Fig. 11. From the slope value in Fig. 11 and the relations below calculated thermodynamic data as in Table 1:

$$
\begin{gathered}
\text { Slope }=-\frac{\Delta \mathrm{H}_{\mathrm{ex}}}{2.303 \mathrm{R}} \\
\Delta \mathrm{G}_{\mathrm{ex}}=-\mathrm{RT} \mathrm{LNK}_{\mathrm{ex}} \\
\Delta \mathrm{G}_{\mathrm{ex}}=\Delta \mathrm{H}_{\mathrm{ex}}-\mathrm{T} \Delta \mathrm{S}_{\mathrm{ex}}
\end{gathered}
$$

The small values of $\Delta \mathrm{H}_{\mathrm{ex}}$ reflect the closely neared together ion pair association complex. So that, the large value of $\Delta$ sex appears the method was entropic in region.

Effect of heating time: According to comprehensive method extracted $\mathrm{Fe}^{3+}$ and $\mathrm{Hg}^{2+}$ from $10 \mathrm{~mL}$ aqueous solutions at optimum condition except different times of heating. The results were as in Fig. 12-14. 


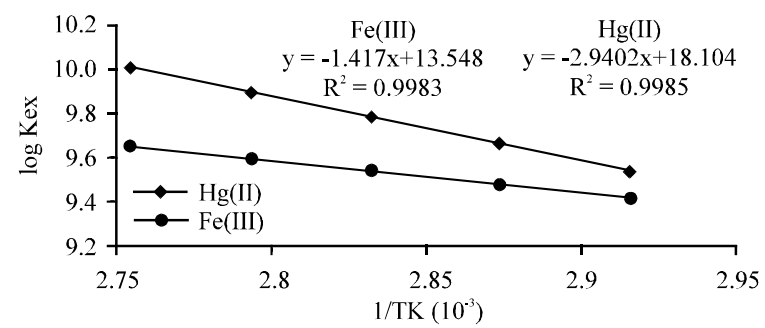

Fig. 12: Effect temperature on extraction constant $\mathrm{K}_{\mathrm{ex}}$

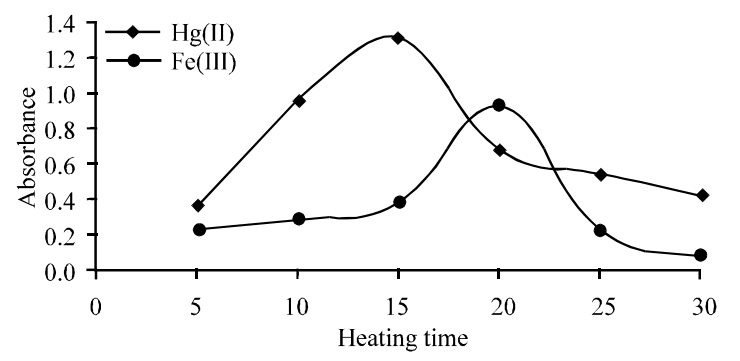

Fig. 13: Heating time effect on CPL formation

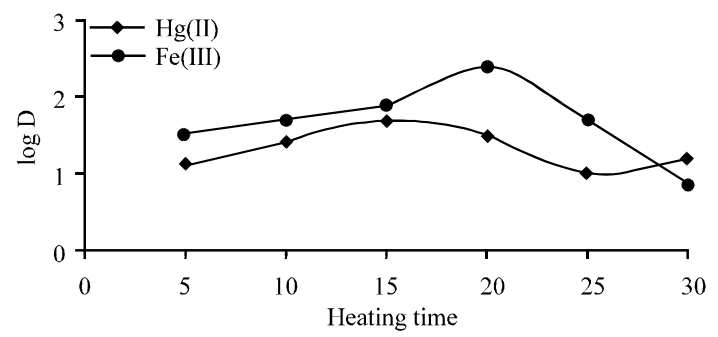

Fig. 14: Heating time effect on extraction efficiency and D values

The results appear optimum heating time was 20 min. for extraction $\mathrm{Fe}^{3+}$ ion and $15 \mathrm{~min}$. for $\mathrm{Hg}^{2+}$ ion whereas the heating time represent the kinetic side of extraction method and at optimum heating time reached to the best kinetic energy of formation CPL and partitioning ion pair association complex to CPL.

Effect of surfactant volume: According to comprehensive method extracted $\mathrm{Fe}^{3+}$ or $\mathrm{Hg}^{2+}$ ions at optimum condition by using different volume of surfactant TritonX-100. The results were as in Fig. 15 and 16.

The results appear optimum surfactant volume was $0.5 \mathrm{~mL}$ TritonX-100 for extraction $\mathrm{Fe}^{3+}$ ion and $0.8 \mathrm{~mL}$ for extraction $\mathrm{Hg}^{2+}$ ion, at this volume of TritonX-100 formed best CPL because this volume allow to reaching critical micelles concentration $\mathrm{CMC}$ and at this state formed CPL with very suitable volume and density with higher dehydration to giving very good layer and phase to quantitative extraction ion pair association complex for

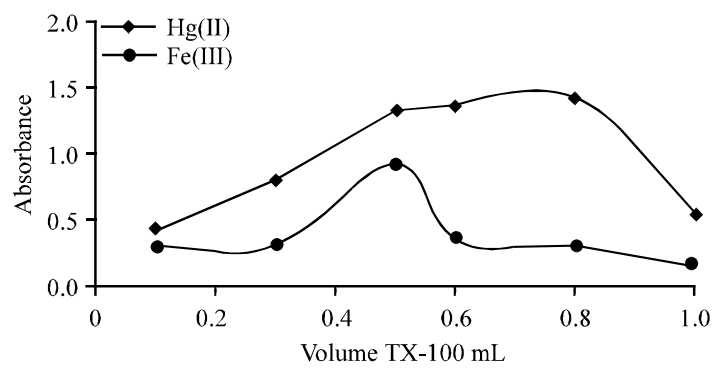

Fig. 15: Effect of Triton X-100 volume on CPL ion pair association complex partition

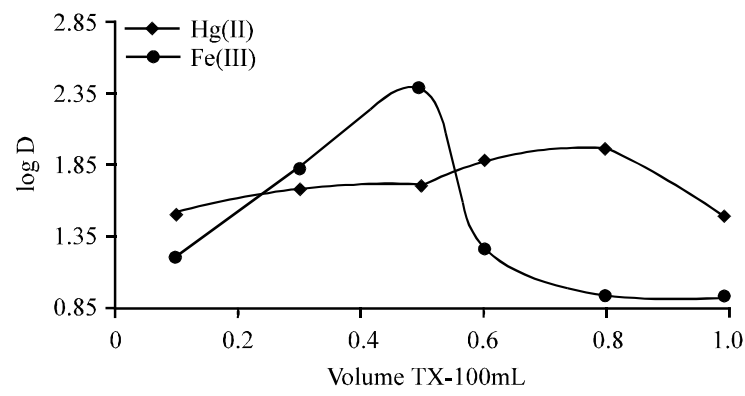

Fig. 16: Effect of Triton X-100 volume on extraction efficiency and D-value

$\mathrm{Fe}^{3+}$ and $\mathrm{Hg}^{2+}$ ions, any volume less than optimum not allow to reached that, so, volume more than optimum effect to increase diffusion of micelles and decrease the favorable properties of CPL and decline in extraction efficiency.

Effect of electrolytes and Interferences: Extracted $100 \mu \mathrm{g}$ of $\mathrm{Fe}^{3+}$ and $\mathrm{Hg}^{2+}$ from $10 \mathrm{~mL}$ aqueous solutions at optimum condition and in the existence of $0.01 \mathrm{M}$ of different electrolytes or foreign ions, according to comprehensive method, the results were as in Table 2 and 3 .

The results show enhancement in extraction efficiency $\mathrm{Fe}^{3+}$ and $\mathrm{Hg}^{2+}$ in the presence of electrolyte because the electrolyte effect to destroying the hydration shell of metal ion and increase formation anion chloro complex, so that, increase dehydration to formation CPL at $\mathrm{CMC}$ with very good proportion to increase the partitioning ion pair complex formed into CPL and increase extraction efficiency, this behavior reflected to metal ions radius of electrolyte smaller volume cation giving higher electrolyte effect then $\mathrm{LiCl}$ giving the higher extraction efficiency. The results appear there was an interferences for all these foreign metal cation in extraction method effect to decrease extraction efficiency of $\mathrm{Fe}^{3+}$ and $\mathrm{Hg}^{2+}$ ions and there is partially effect for each ion depending on the different behavior of each ion in extraction method 


\begin{tabular}{|c|c|c|c|c|}
\hline \multirow[b]{2}{*}{ Electrolyte salts } & \multicolumn{2}{|l|}{$\mathrm{Fe}^{3+}$} & \multicolumn{2}{|l|}{$\mathrm{Hg}^{2+}$} \\
\hline & Abs. $477 \mathrm{~nm}$ & $\mathrm{D}$ & Abs. $476 \mathrm{~nm}$ & $\mathrm{D}$ \\
\hline $\mathrm{LiCl}$ & 0.615 & 122.50 & 1.721 & 110.55 \\
\hline $\mathrm{NaCl}$ & 0.565 & 110.20 & 1.671 & 105.63 \\
\hline $\mathrm{KCl}$ & 0.495 & 102.40 & 1.576 & 100.14 \\
\hline $\mathrm{NH}_{4} \mathrm{Cl}$ & 0.425 & 096.30 & 1.483 & 094.71 \\
\hline $\mathrm{MgCl}_{2}$ & 0.587 & 115.70 & 1.691 & 107.55 \\
\hline $\mathrm{CaCl}_{2}$ & 0.525 & 099.60 & 1.531 & 098.32 \\
\hline
\end{tabular}

\begin{tabular}{llclc}
\multicolumn{5}{c}{ Table 3: Effect of interferences on extraction efficiencies } \\
\hline & $\mathrm{Fe}^{3+}$ & \multicolumn{3}{l}{$\mathrm{Hg}^{2+}$} \\
\cline { 2 - 5 } Interferences & Abs. $477 \mathrm{~nm}$ & $\mathrm{D}$ & $\mathrm{Abs} .476 \mathrm{~nm}$ & $\mathrm{D}$ \\
\hline $\mathrm{Ni}^{2+}$ & 0.170 & 17.15 & 0.668 & 40.21 \\
$\mathrm{Co}^{2+}$ & 0.315 & 50.30 & 0.432 & 30.50 \\
$\mathrm{Cd}^{2+}$ & 0.221 & 32.80 & 0.659 & 38.22 \\
$\mathrm{Cu}^{2+}$ & 0.198 & 24.40 & 0.556 & 32.46 \\
$\mathrm{Zn}^{2+}$ & 0.199 & 25.30 & 0.616 & 36.75 \\
$\mathrm{Mn}^{2+}$ & 0.181 & 21.60 & 0.321 & 26.71 \\
\hline
\end{tabular}

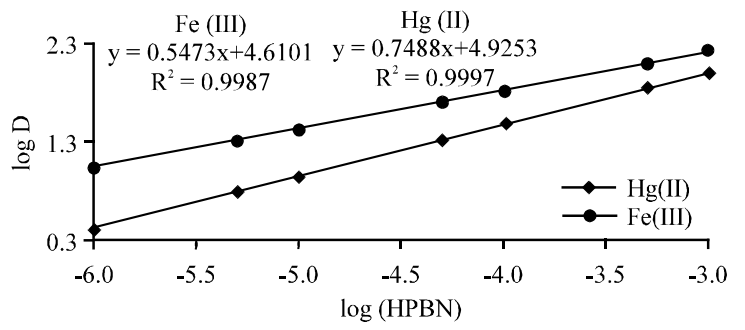

Fig. 17: Slope analysis for $\mathrm{Fe}^{3+}$ and $\mathrm{Hg}^{2+}$ ions

and interferences of these ion mean participation of each one of these ions to formation ion pair association complex and this participation effect to decline concentration of $\mathrm{HCl}$ and $\mathrm{HPBN}$, less than optimum values necessary to extraction $\mathrm{Fe}^{3+}$ and $\mathrm{Hg}^{2+}$ ions.

Stoichiometry: For demonstrated the more probable structure of ion pair association complexes extracted to CPL following two spectrophotometric method, the first method was slope analysis involved extracted metal ions $\mathrm{Fe}^{3+}$ and $\mathrm{Hg}^{2+}$ according to comprehensive method at optimum condition, the results were as in Fig. 17.

So that, following the slope ratio as spectrophotometric method according to comprehensive method at optimum condition in variation metal concentration time and at different concentration of HPBN twice, the results were as in Fig. 18 and 19.

Applications: For spectrophotometric determination of $\mathrm{Fe}^{3+}$ and $\mathrm{Hg}^{2+}$ in different environmental and vital samples followed, the comprehensive method for extraction metal ion under study from $10 \mathrm{~mL}$ aqueous solutions contain different quantity of metal cation at

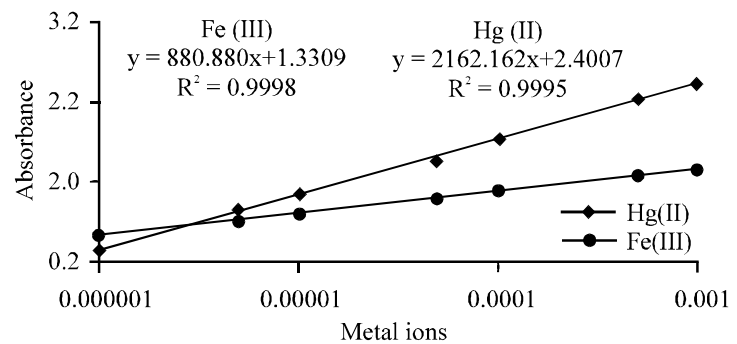

Fig. 18: Effect of HPBN concentration on the absorbance of ion pair complex extracted Slope ratio for $\mathrm{Hg}^{2+}=2162.162 / 2162.162=1.000$

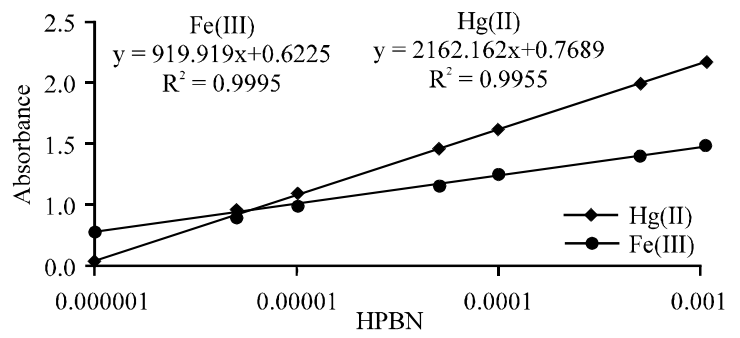

Fig. 19: Effect of variation metal ion concentration on the absorbance of ion pair complex extracted Slope ratio for $\mathrm{Fe}^{3+}=919.919 / 880.880$ $=1.044$

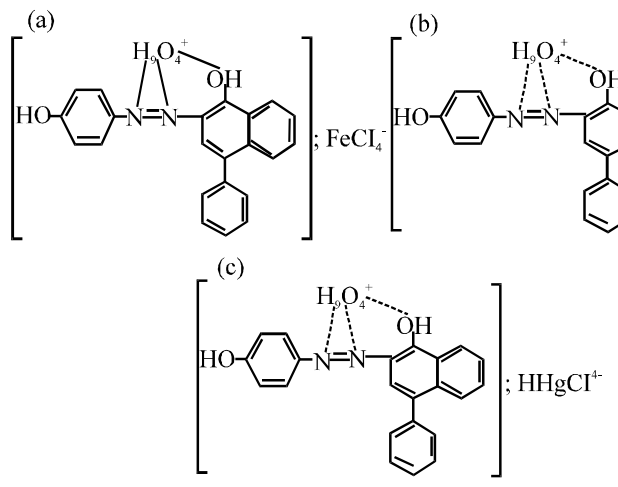

Fig. 20: a-c) Plot obserbance against ppm of metal

optimum conditions and after separated CPL from aqueous solutions and dissolved CPL in $5 \mathrm{~mL}$ ethanol and measure absorbance for ethanolic solutions against blank prepared in the same manner without metal ions, then plot absorbance against ppm of metal ion as in Fig. 20 and 21. Any sample after preparing treated according to comprehensive method at optimum condition after measure the absorbance and return to calibration curve for each metal ion determine metal ion in the sample. The results were as in Table 4. 
Table 4: $\mathrm{Fe}^{3+} \mathrm{and}_{\mathrm{Hg}}{ }^{2+}$ content (ppm) in different samples

\begin{tabular}{|c|c|c|c|c|c|c|}
\hline \multirow[b]{2}{*}{ Samples } & \multicolumn{3}{|l|}{$\mathrm{Fe}^{3+}$} & \multicolumn{3}{|l|}{$\mathrm{Hg}^{2+}$} \\
\hline & Thiocyanate method & Applied method* & $\operatorname{RSD}(\%)$ & Dithizone method & Applied method* & $\mathrm{RSD}(\%)$ \\
\hline Agriculture 1 & 13.50 & 13.80 & 0.12 & 0.18 & 0.17 & 0.02 \\
\hline Agriculture 2 & 20.60 & 20.80 & 0.02 & 0.20 & 0.19 & 0.03 \\
\hline Cow meat & 01.50 & 01.60 & 0.14 & 0.16 & 0.17 & 0.01 \\
\hline Chicken (breast) & 07.20 & 07.10 & 0.12 & 0.16 & 0.16 & 0.05 \\
\hline Drainage fish & 17.10 & 17.10 & 0.02 & 0.60 & 0.62 & 0.09 \\
\hline River water & 01.00 & 01.10 & 0.01 & 0.48 & 0.48 & 0.01 \\
\hline Garden cress & 06.30 & 06.28 & 0.13 & 0.40 & 0.41 & 0.14 \\
\hline Celery & 05.00 & 04.90 & 0.15 & 0.10 & 0.11 & 0.12 \\
\hline Lettuce & 06.80 & 06.50 & 0.11 & 0.15 & 0.16 & 0.14 \\
\hline Cucumber & 05.00 & 04.94 & 0.01 & 0.08 & 0.05 & 0.17 \\
\hline Tomato & 08.60 & 08.50 & 0.03 & 0.04 & 0.03 & 0.05 \\
\hline
\end{tabular}

*Values given represent the average of five analysis of each sample

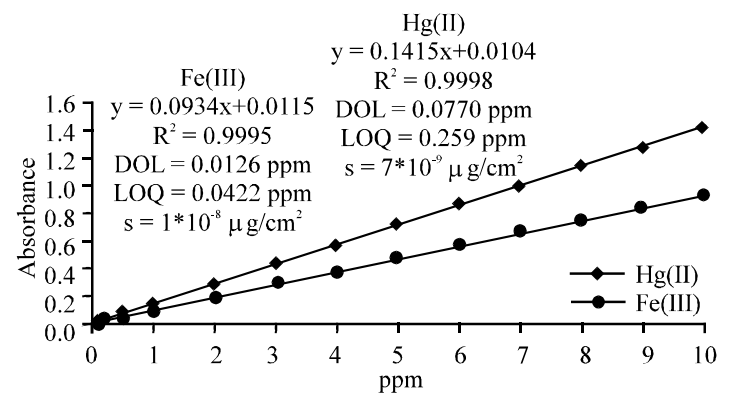

Fig. 21: Calibration curve for spectrophotometric determination of $\mathrm{Fe}^{3+}$ and $\mathrm{Hg}^{2+}$ by joined method

\section{CONCLUSION}

As well as the research involved other studies such as electrolyte effect interferences effect, application for determination of $\mathrm{Fe}^{3+}$ ion and $\mathrm{Hg}^{2+}$ ion in biologic samples (Jawad et al., 2017).

\section{ACKNOWLEDGEMENTS}

This research was supported by The Chemistry Department in Faculty of Education for Women in University of Kufa in Iraq.

\section{REFERENCES}

Jawad, S.K. and E.A. Azooz, 2014. Cloud point extraction for separation, preconcentration and extraction of nickel (II) as chloroanion by use crown ether DB18C6 coupled with spectrophotometric determination. Intl. J. Sci. Technol., 9: 17-23.

Jawad, S.K. and E.A. Azooz, 2015b. A new approach for separation, extraction and determination of zinc in different samples using cloud-point extraction coupled with spectrophotometry. Fire J. Sci. Technol., 3: 261-273.
Jawad, S.K. and E.A. Azooz, 2015a. Cloud point extraction method for separation and PRE concentration of $\mathrm{MG}$ (II) as anion coupled with spectrophotometric applications. Impact J. Res. Appl. Nat. Soc. Sci., 1: 119-134.

Jawad, S.K. and F.H. Hayder, 2015. Cloud point extraction, preconcentration and spectrophotometric determination of magnesium(ii) by using 2,4-dimethylpentan-3-one. Eur. Chem. Bull., 4: $360-363$.

Jawad, S.K. and M.N.M. Salih, 2015. Cloud point extraction methodology for separation and extraction Platinum (II) as Chloro complex anion coupled with spectrophotometric method for determination in different samples. J. Nat. Sci. Res., 5: 195-201.

Jawad, S.K. and S.M. Hameed, 2017. Extraction of $\mathrm{Cd}$ (II)and $\mathrm{Hg}$ (II) by Liquid Ion Exchange Methodology. 1st Edn., Noor Publishing, Saarbrucken, Germany,

Jawad, S.K., M.O. Kadhim and E.A. Azooz, 2017. Incorporation of onium system with cloud point extraction and determination of Iron (III) and mercury (II) in different samples. Oriental J. Chem., 33: 1879-1889.

Marczenko, Z. and M. Balcerzak, 2000. Separation, Preconcentration and Spectrophotometry in Inorganic Analysis. 1st Edn., Elsevier, Amsterdam, Netherlands, Pages: 514.

Samaddar, P. and K. Sen, 2014. Cloud point extraction: A sustainable method of elemental preconcentration and speciation. J. Ind. Eng. Chem., 20: 1209-1219.

Shibata, S., M. Furukawa and R. Nakashima, 1976. Syntheses of azo dyes containing 4, 5diphenylimidazole and their evaluation as analytical reagents. Anal. Chimica Acta, 81: 131-141.

Tokalioglu, S., S. Kartal and L. Elci, 2000. Determination of heavy metals and their speciation in lake sediments by flame atomic absorption spectrometry after a four-stage sequential extraction procedure. Anal. Chim. Acta, 413: 33-40. 